\title{
Composite Permeability Model of Shale Matrix with the Effect of Adsorption
}

\author{
Cheng $\mathrm{Cao}^{1,2^{*}}$, Tiantai $\mathrm{Li}^{2}$ and Bojiang Fan $^{2}$ \\ ${ }^{1} 18$ Fuxue Road Changping, Beijing 102249, China \\ ${ }^{2} 75$ Keji-2 Road Yanta, Xi'an 710075, China \\ *Corresponding author
}

\begin{abstract}
The shale matrix is composed of organic matter and inorganic matter. Methane often adsorbs in organic pores and water adsorbs in inorganic matter. Adsorption layer blocked the spaces of pores, and leads to the decrease of porosity and permeability. However, the influence of adsorption layer on shale permeability is neglected on present research. As a result, the value of calculated Composite Permeability is larger than its true value. Considering the adsorption, slippage and free molecule flow effects, this paper proposes the organic permeability model, inorganic permeability model and composite permeability model based on capillary calculation model and existing apparent permeability calculation model. In comparison with the experimental results, it is found that the proposed model help to get the reliable results and it is more practical in predicting the shale gas reservoir permeability. Also, the proposed model is used to predict shale permeability of Shan-xi Formation, Paleozoic, Ordos basin, China. The results show that: (1) At the beginning time of development (the pressure is 30MPa), the decreasing of the permeability in organic matter is sensitive when pore diameter is less than $10 \mathrm{~nm}$. At the late stage of development (the pressure is $5 \mathrm{MPa}$ ), the smaller the organic pore diameters are, the greater the permeability in organic matter will increase (2) With the decreasing of pressure and increasing of Langmuir pressure, the increasing rate of permeability increases.(3) with the increasing of water saturation, the damage of inorganic permeability becomes serious.
\end{abstract}

Keywords-shale gas; organic permeability; inorganic permeability; composite permeability; slippage; free molecule flow

\section{INTRODUCTION}

In recent years, shale gas, an important replacement of conventional oil and gas, has taken an important strategic position. Shale gas exploration and development is expanding from North America to Global [J.Y. Xu. 2010]. Shale gas reservoir becomes the research hot spot for its abundant resources [J. Yao. 2013, J.C. Zhang. 2004]. In China, the research of reservoiring mechanism and geological characteristics has made some advancement. However, the understanding of shale gas seepage still stays in the initial stage for the complexity of geological factors such as Micro/Nano scale pores, heterogeneity. In fact, matrix permeability is the most reliable factor for reflecting the gas seepage law. Most of current research on shale matrix permeability is based on Darcy permeability, and considers the slippage and Knudsen diffusion (free molecular flow) [S.S. Gao], the effects of stress sensitive and the matrix shrinkage [Z.P. L.2012, L. Palmer. 1996].
Javadpour investigated the gas migration in Nano-porous and established the apparent permeability model considering gas slippage and Knudsen diffusion [F. Javadpour. 2009]. However, the effect of the adsorption layer on permeability has been ignored. Adsorption layer reduces the moving ability of fluid in the pores, and affect shale matrix permeability indirectly [P.A. Sakhaee. 2011].

Considering the effect of adsorbed gas, adsorption water, slippage and free molecular flow, this paper proposes a new shale permeability model. This new permeability model is also used to estimate the shale permeability of Shan Xi Formation, Paleozoic, Ordos basin, China.

\section{EFFECT OF ADSORPTION, SLIPPAGE AND FREE MOLECULAR FLOW}

\section{A. Effect of Adsorption}

For the shale pores on Micro/nano scale, the thickness of adsorption layer on the pore wall is nearly the same order of matrix pore size, the existence of the adsorption layer result in the reducing of the cross section of pores channel, and thus affect the matrix permeability. Methane mainly adsorbs in organic pores wall [Q.R. Passey. 2010], and the effect of adsorption layer on permeability in organic matter vary with pore pressure. Adsorption layer on pore wall is mainly water in inorganic matter, and the effect of adsorption layer in inorganic changes with water saturation.

\section{B. Effect of Slippage and Free Molecular Flow}

Slippage and free molecular flow effect is the macro performance of gas molecules collision with the pore wall. When the gas molecular mean free path is close to pores size, the probability of collision between gas molecules and pore wall will increase, and the slippage will happen. When the gas molecular mean free path is larger than the pore channels, the collision between gas molecular and pore wall becomes very strong, and free molecule flow will happen. Slippage and free molecular flow make it easier for gas to pass through the pore channel, and affect the permeability[J.T. Shi. 2013, H. TIAN. 2012, F. Czvan. 2010, Y. Li. 2014, F. Javadpour. 2007]. The effect of slippage and free molecular flow on shale permeability can be represented by using apparent permeability model. 


$$
k_{a p}=\frac{\phi D^{2}}{32 \tau^{2}}\left[\frac{4.5^{4}(1+5 K n)}{4.5^{4}+K n^{4}}+\left(\frac{128 \tau^{2} \mu_{g} \delta^{2}}{3 K_{B} \phi} \sqrt{\frac{\pi R}{M T}}\right)\left(\frac{K \mathrm{n}^{5}}{4.5^{4}+K n^{4}}\right)\right]
$$

\section{Establishment OF PERMEABILITy MODEL}

Model assumption: Assuming that shale unit is composed of $\mathrm{n}$ organic tube and $\mathrm{m}$ inorganic tube, length of unit is $\mathrm{L}$, cross section area of unit is A. a is organic matter content in shale matrix. Organic pores size is $\mathrm{R}_{\mathrm{org}}$, and the effective pores diameter is $D_{\text {org, }, ~}$ at the initial pressure condition. Effective pores diameter is $D_{\text {org, }}$. When pressure is decreased by $p$ (Figure- I -left). Initial effective pores diameter of inorganic matter is $D_{\text {inorg, } 0}$ and effective pores diameter is $D_{\text {inorg }}$ when water saturation is $S_{w}$ (Figure- I -right). Wettability and pores size between organic and inorganic is different, and thus the shale organic permeability and inorganic permeability is also different.

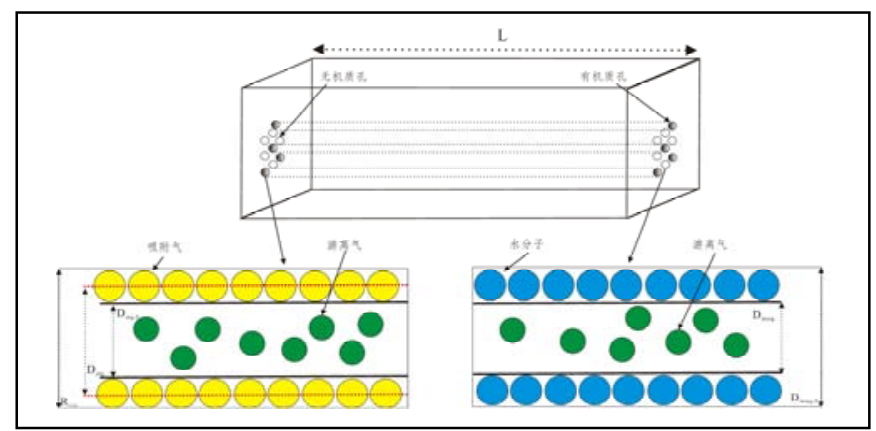

FIGURE I. GAS FLOW IN NANOPORES SYSTEM.

\section{A. ESTABLISHMENT of Oganic Permeability Model}

Define abbreviations and acronyms the first time they are used in the text, even after they have been defined in the abstract. Abbreviations such as IEEE, SI, MKS, CGS, sc, dc, and rms do not have to be defined. Do not use abbreviations in the title or heads unless they are unavoidable.

Adsorption water in organic pores is ignored. Adsorption gas on organic pores wall can be represented by Langmuir equation as Eq.(2)

$$
V=\frac{V_{\mathrm{m}} p}{p_{L}+p}
$$

where, $V_{\mathrm{m}}$ is Langmuir Volume, $\mathrm{m} 3 / \mathrm{t}$; $\mathrm{pL}$ is Langmuir pressure, $\mathrm{MPa} ; V$ is adsorption volume, $\mathrm{m} 3 / \mathrm{t}, p$ is pores pressure, $\mathrm{MPa}$.

In initial pressure $p_{0}$, adsorption volume of shale unit is $V_{0}$

$$
V_{0}=\frac{V_{\mathrm{m}} p_{0}}{p_{L}+p_{0}}=\frac{n \pi L}{4}\left(R_{\mathrm{org}}^{2}-D_{\text {org }, 0}^{2}\right) .
$$

When pores pressure is decreased by $\mathrm{p}$, adsorption volume of shale unit is $V$

$$
V=\frac{V_{\mathrm{m}} p}{p_{L}+p}=\frac{n \pi L}{4}\left(R_{\mathrm{org}}^{2}-D_{o r g, p}^{2}\right)
$$

Divide Eq (4) by Eq (3), and after simplify, the ration of effective pores diameter at pressure $p$ and initial pressure $p 0$ is obtained.

$$
\frac{D_{\text {org, },}}{D_{\text {org }, 0}}=\frac{R_{\text {org }}}{D_{\text {org }, 0}}\left[1-\left(\frac{p}{p_{L}+p} \cdot \frac{p_{L}+p_{0}}{p_{0}}\right) \times\left(1-\frac{D_{\text {org, },}{ }^{2}}{R_{\text {org }}{ }^{2}}\right)\right]^{0.5} .
$$

Effective Porosity of organic tube as Eq.(6):

$$
\phi_{o r g, p}=n \cdot \frac{\pi D_{o r g, p}^{2} L}{4 A \cdot a L} .
$$

Consider $\mathrm{Eq}(6)$, the ration of effective porosity at pressure $\mathrm{p}$ and initial pressure $\mathrm{p} 0$ is obtained.

$$
\frac{\phi_{\text {org }, \mathrm{p}}}{\phi_{\text {org }, 0}}=\frac{R_{\text {org }}^{2}}{D_{\text {org, }, 0}^{2}}\left[1-\left(\frac{p}{p_{L}+p} \cdot \frac{p_{L}+p_{0}}{p_{0}}\right) \times\left(1-\frac{D_{\text {org, },}{ }^{2}}{R_{\text {org }}{ }^{2}}\right)\right] .
$$

Substitute $\operatorname{Eq}(5)$ and $\operatorname{Eq}(7)$ into $\operatorname{Eq}(1)$, and define adsorption gas influence factor as Eq.(8)

$$
\varepsilon=\frac{R_{\text {org }}}{D_{\text {org }, 0}}\left[1-\left(\frac{p}{p_{L}+p} \cdot \frac{p_{L}+p_{0}}{p_{0}}\right) \times\left(1-\frac{D_{\text {org }, 0}{ }^{2}}{R_{\text {org }}{ }^{2}}\right)\right]^{0.5} .
$$

Organic permeability model considering adsorption gas, slippage and free molecule flow is obtained.

$$
k_{\text {org }}=\varepsilon^{4} \cdot \frac{\phi_{\text {org }, 0} D_{\text {org, }}{ }^{2}}{32 \tau^{2}} \cdot\left[\frac{4.5^{4}\left(1+5 K n \cdot \varepsilon^{-1}\right)}{4 \cdot 5^{4}+\left(K n \cdot \varepsilon^{-1}\right)^{4}}+\left(\frac{128 \tau^{2} \mu_{g} \delta^{2}}{3 K_{B} \cdot \phi_{\text {org }, 0} \varepsilon^{2}} \sqrt{\frac{\pi R}{M T}}\right)\left(\frac{\left(K n \cdot \varepsilon^{-1}\right)^{5}}{4 \cdot 5^{4}+\left(K n \cdot \varepsilon^{-1}\right)^{4}}\right)\right]
$$

\section{B. Establishment of Inorganic Permeability Model}

Adsorption gas in inorganic pores is ignored. When effective pores diameter is Dinorg water saturation is $\mathrm{Sw}$

$$
S_{\mathrm{w}}=\frac{\pi \cdot D_{\text {inorg, } 0}{ }^{2} L / 4-\pi \cdot D_{\text {inorg }}^{2} L / 4}{\pi \cdot D_{\text {inorg }, 0}{ }^{2} L / 4}=1-\frac{D_{\text {inorg }}^{2}}{D_{\text {inorg }, 0}^{2}} .
$$

Simplify to:

$$
\frac{D_{\text {inorg }}}{D_{\text {inorg }, 0}}=\left(1-S_{\mathrm{w}}\right)^{0.5}
$$

Consider the relationship between pores diameter and porosity, the ration of effective porosity at water saturation $\mathrm{Sw}$ and initial condition is obtained. 


$$
\frac{\phi_{\text {inorg }}}{\phi_{\text {inorg }, 0}}=1-S_{\mathrm{w}}
$$

Substitute $\mathrm{Eq}(11)$ and $\mathrm{Eq}(12)$ into $\mathrm{Eq}(1)$, and define adsorption gas influence factor as $\mathrm{Eq}(13)$.

$$
\eta=\left(1-S_{\mathrm{w}}\right)^{0.5}
$$

Inorganic permeability model considering adsorption water, slippage and free molecule flow is obtained.

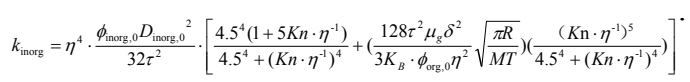

\section{Establishment of Composite Permeability Model}

Gas flowing through organic pores and inorganic pores respectively in the differential pressure. The total gas mass flow $(J)$ is consisted of gas mass flow in organic pores $\left(\mathrm{J}_{\text {org }}\right)$ and gas mass flow in inorganic pores $\left(\mathrm{J}_{\text {inorg }}\right)$.

$$
J=J_{\text {org }}+J_{\text {inorg }}
$$

where:

$$
\begin{gathered}
J_{\text {org }}=\frac{\rho k_{\text {org }} \cdot A a}{\mu_{g}} \nabla p . \\
J_{\text {inorg }}=\frac{\rho k_{\text {inorg }} \cdot A(1-a)}{\mu_{g}} \nabla p .
\end{gathered}
$$

where, $\rho$ is gas density, $\mathrm{kg} / \mathrm{m} 3 ; \nabla p$ is pressure gradient, $\mathrm{MPa}$.

Substitute $\operatorname{Eq}(16)$ and $\operatorname{Eq}(17)$ into $\operatorname{Eq}(15)$, The total gas mass flow is derived as:

$$
J=\frac{\rho A}{\mu_{g}} \cdot\left[k_{\text {org }} a+k_{\text {inorg }}(1-a)\right] \nabla p
$$

Define composite permeability as $\operatorname{Eq}(19)$

$$
k=k_{\text {org }} a+k_{\text {inorg }}(1-a) \text {. }
$$

Substitute $\mathrm{Eq}(9)$ and $\mathrm{Eq}(14)$ into $\mathrm{Eq}(19)$, composite permeability is derived as:

$$
\begin{aligned}
& k=a \cdot \varepsilon^{4} \cdot \frac{\phi_{\text {org }, 0} D_{\text {org }, 0}{ }^{2}}{32 \tau^{2}} \cdot\left[\frac{4.5^{4}\left(1+5 K n \cdot \varepsilon^{-1}\right)}{4.5^{4}+\left(K n \cdot \varepsilon^{-1}\right)^{4}}+\left(\frac{128 \tau^{2} \mu_{g} \delta^{2}}{3 K_{B} \cdot \phi_{\text {org }, 0} \varepsilon^{2}} \sqrt{\frac{\pi R}{M T}}\right)\left(\frac{\left(K \mathrm{n} \cdot \varepsilon^{-1}\right)^{5}}{4.5^{4}+\left(K n \cdot \varepsilon^{-1}\right)^{4}}\right)\right] \\
& +(1-a) \cdot \eta^{4} \cdot \frac{\phi_{\text {inorg, } 0} D_{\text {inorg }, 0} 0^{2}}{32 \tau^{2}} \cdot\left[\frac{4.5^{4}\left(1+5 K n \cdot \eta^{-1}\right)}{4.5^{4}+\left(K n \cdot \eta^{-1}\right)^{4}}+\left(\frac{128 \tau^{2} \mu_{g} \delta^{2}}{3 K_{B} \cdot \phi_{\text {inorg }, 0} \eta^{2}} \sqrt{\frac{\pi R}{M T}}\right)\left(\frac{\left(K \mathrm{n} \cdot \eta^{-1}\right)^{5}}{4.5^{4}+\left(K n \cdot \eta^{-1}\right)^{4}}\right)\right] .
\end{aligned}
$$

\section{MODEL VALIDATION}

Experimental data in literature [S.S. Gao, 2011] is used to verify organic permeability model. Parameters used in organic permeability model is same with the parameters obtained from experimental cores. The comparison of organic permeability model and experimental results are showed in figure- II -left. Adsorption gas is not considered in J.T.SHI permeability model, thus the ration of apparent permeability $(\mathrm{kg})$ calculated by using J.T.SHI permeability model to absolute permeability $\left(\mathrm{k}_{\infty}\right)$ is lower than that obtained from experimental results. For the proposed organic permeability model, the calculating result of organic permeability model is match with experimental result when pore pressure is higher than $3 \mathrm{MPa}$. Generally, the pressure of actual gas reservoir is higher than $3 \mathrm{MPa}$, and thus the organic permeability model proposed in this paper can predict the actual shale gas reservoir permeability accurately. Inorganic permeability model is verified by using experimental data in literature [Y. Qi, 2005] parameters, such as lithology, wettability and pores size of experimental core is identical to parameters of inorganic permeability model. Variation trend of experimental inorganic permeability is the same with inorganic permeability obtained by using the model proposed in this paper, so it proves that inorganic permeability model is reliable. Composite permeability model is accuracy when organic permeability model and inorganic permeability model is reliable.

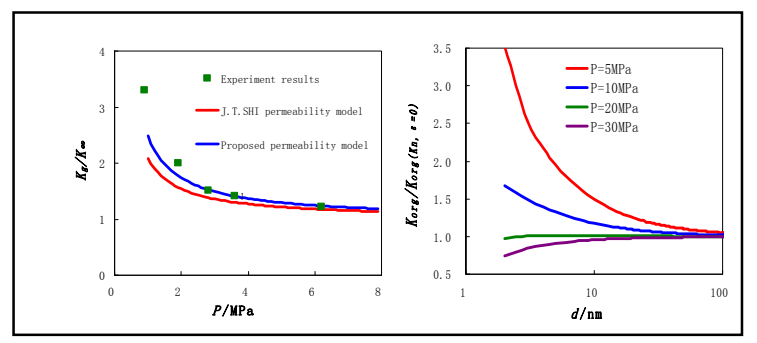

FIGURE II. VERIFICATION OF ORGANIC PERMEABILITY MODEL(LEFT) AND EFFECT ON ORGANIC PERMEABILITY(RIGHT)

\section{APPLiCATION TO THE FIELD}

Total organic carbon of shale is adequate in Shanxi Formation, Paleozoic, Ordos basin, China. Most of pore diameters in organic matter are less than $10 \mathrm{~nm}$, and pore diameters in inorganic matter are relatively large. Pore pressure is higher than $3 \mathrm{MPa}$. As discussed above this model can be used to predict shale matrix permeability in this field. Parameters of this field is showed in table 1

TABLE I. TABLE TYPE STYLES.

\begin{tabular}{|c|c|c|c|}
\hline parameters & value & parameters & value \\
\hline$\mu_{g} /(\mathrm{Pa} \cdot \mathrm{s})$ & 0.000023 & $\tau$ & 1 \\
\hline$\varphi_{\text {inorg }, 0}$ & 0.06 & $\delta / \mathrm{m}$ & $4.1 \times 10^{-10}$ \\
\hline$T / \mathrm{K}$ & 323 & $M /(\mathrm{kg} / \mathrm{mol})$ & 0.0195 \\
\hline$R /\left(\mathrm{Pa} \cdot \mathrm{m}^{3} \cdot \mathrm{K}^{-1} \cdot \mathrm{kmol}^{-1}\right)$ & 8314 & $V_{m} /\left(\mathrm{m}^{3} / \mathrm{t}\right)$ & 2 \\
\hline$\varphi_{\text {org, } 0}$ & 0.02 & $P_{0} / \mathrm{MPa}$ & 30 \\
\hline$p_{L} / \mathrm{MPa}$ & 4.54 & $a / \%$ & $0 \sim 100$ \\
\hline$K_{B} /(\mathrm{J} / \mathrm{K})$ & $1.38 \times 10^{-23}$ & $R_{\text {org }} / \mathrm{nm}$ & 7.2 \\
\hline
\end{tabular}


The effects of adsorption gas, slippage and free molecule flow on organic permeability at different pressures and pore sizes are showed in figure- II - right. The higher the pore pressure is, the lower the ration of organic permeability considered adsorption gas, slippage and free molecule flow to organic permeability unconsidered adsorption gas, slippage and free molecule flow. When pressure reaches to $30 \mathrm{MPa}$, the influence of slippage is small, and with the decreasing of pore diameters, the ratio is gradually lower than 1 , and the effect of adsorption gas is increasing. With the pressure keeping down, the combined effect of slippage, desorption and free molecule flow effect is start working, so the ratio is increasing with the decreasing of pores size.

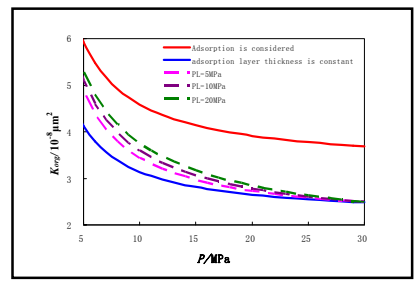

FIGURE III. THE DYNAMIC CHARACTERISTIC OFORGANIC PERMEABILITY.

Langmuir pressure is an important factor for isothermal adsorption. The thickness of adsorption layer are presumed to be $0.7 \mathrm{~nm}$ in organic matter, and the average pore diameter is $7.2 \mathrm{~nm}$ in this field. The result is show in figure- III. The existence of adsorption layer reduces the organic permeability. But with the decreasing of the pore pressure, the thickness of adsorption layer is reducing, and slippage increase, so the organic permeability is gradually increasing. Different Langmuir pressure shows different desorption speed.

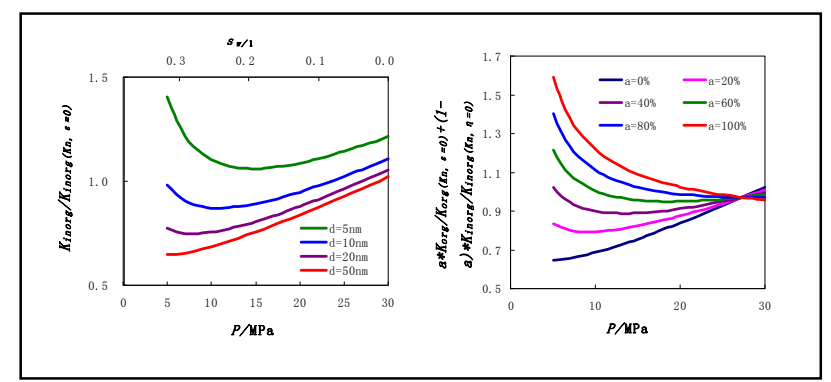

FIGURE IV. THE EFFECT ON INORGANIC PERMEABILITY(LEFT) AND EFFECT ON CONPOSITE PERMEABILITY(RIGHT).

In the development processing, water saturation in inorganic matter is at the range of $0 \%$ to $38 \%$. It can be Seen from figure-IV-left that, the larger the pore diameter is, the lower the ratio of permeability which considered adsorption water, slippage and free molecule flow $\left(\mathrm{k}_{\text {inorg }}\right)$ to permeability in inorganic matter unconsidered adsorption water, slippage and free molecule flow $\left(\mathrm{k}_{\mathrm{inorg}(\mathrm{Kn}, \eta=0)}\right)$ is. When pore diameter is $50 \mathrm{~nm}$, the influence of slippage is small, and the cross section of pores channel reduces with the increasing of water saturation, so the corresponding permeability in inorganic matter decreases. When pore diameter is less than $10 \mathrm{~nm}$, permeability in inorganic matter decreases at first and then increases with the increasing of water saturation.
The relationship between composite permeability and pore pressure is showed in figure-IV-right. It can be seen that when organic matter content is $100 \%$, composite permeability is equal to permeability in organic. When organic matter content is $80 \%$, composite permeability is larger than that which organic matter content is $100 \%$ at the early stage of production. But composite permeability is lower than that which organic matter content is $100 \%$ as the increasing of water saturation in inorganic pores. When organic matter content is $0 \%$, composite permeability is equal to inorganic permeability.

\section{SUMMARY}

1) It proves that this model is reliable to estimate the organic permeability, inorganic permeability and composite permeability. Also, Errors caused by adsorption and deviation from the difference between organic permeability and inorganic permeability can be modified by using this model.

2) The influence of adsorption gas on organic permeability cannot be ignored. At the beginning stage of shale gas development, the influence of adsorption gas plays an important role, At the late stage of shale gas development, the smaller the pore diameters are, the greater the effect of slippage and free molecule flow plays.

3) The influence of adsorption water mainly happens in late stage of shale gas development, and the larger the inorganic pore diameter are, the greater the effect of adsorption on inorganic permeability plays.

\section{ACKNOWLEDGMENT}

This research was financially supported by the National high technology research and development program (863 program).

\section{REFERENCES}

[1] J.Y. Xu, A.J. Wu, The development status of shale gas in the world and its exploration prospect in China, Special Oil and Gas Reservoirs, 17 (2010) 2-7.

[2] J. Yao, H. Sun, D.M. Fan, Transport mechanisms and numerical simulation of shale gas reservoirs, Journal of China University of Petroleum, 37(2013) 91-98.

[3] J.C. Zhang, Z.J. Jin, M.S. Yuan, Reservoiring mecahnism of shale gas and its distribution, Natural Gas Industry, 24 (2004) 5-18.

[4] S.S. Gao, X.H.Yu, H.X. Liu, Impact of slippage effect on shale gas well productivity, Natural Gas Industry, 31(2011) 55-58.

[5] Z.P. L, Z.F. Li, Dynamic characteristics of shale gas flow in nanoscale pores, Natural Gas Industry, 32 (2012) 50-53.

[6] L. Palmer, J. Mansoori, How Permeability Depends on Stress and Pore Pressure in Coalbeds: A New Model[C]. SPE Annual Technical Conference and Exhibition. Denver, Colorado, USA: Society of Petroleum Engineers, 1996.

[7] F. Javadpour, Nanopore and apparent permeability of gas flow in mud rocks (shale and siltstone). Journal of Canadian Petroleum Technology, 2009, 48(8):16-21.

[8] P.A. Sakhaee, S.L. Bryant. Gas Permeability of Shale, SPE Annual Technical Conference and Exhibition. Denver, Colorado, USA: Society of Petroleum Engineers, 2011.

[9] Q.R. Passey, K.M. Bohacsk, W.L. Esch, From Oil-Prone Source Rock to Gas-Producing Shale Reservoir-Geologic, SPE International Oil and Gas Conference and Exhibition. Beijing, China: Society of Petroleum Engineers, 2010 
[10] J.T. Shi, L. Zhang, Li, Y. S, Diffusion and Flow Mechanisms of Shale Gas through Matrix Pores and Gas Production Forecasting[C]. SPE Unconventional Resources Conference. Calgary, Alberta, Canada: Society of Petroleum Engineers, 2013.

[11] H. TIAN, S.C. ZHANG, S.B. LIU, Determination of organic-rich shale features by mercury injection and gas adsorption method, Acta Petrolei Sinica, 33 (2012) 419-427.

[12] F. Czvan, S.C. Rai, H.C. Sonderceld, Shale gas permeability and diffusivity inferred by improved formulation of relevant retention and transport mechanisms, Transport in porous media, 86 (2010) 925-944.

[13] Y. Li, X. Li, J. Shi, A Nano-Pore Scale Gas Flow Model for Shale Gas Reservoir, SPE Energy Resources Conference. Port, Spain, Trinidad: Society of Petroleum Engineers, 2014.
[14] F. Javadpour, Fisher, Unsworth M, et al. Nanoscale Gas Flow in Shale Gas Sediments, Journal of Canadian Petroleum Technology, 46 (2007) 55-61.

[15] Y.F. Chen, B.X. Dong, X. Shi, Seepage mechanism of a tripleporosity/dual-permeability model for shale gas reservoirs, Natural Gas Industry, 32 (2012) 44-47.

[16] R.J. Ambrose, R.C. Hartman, M.D. Campos, New Pore-scale Considerations for Shale Gas in Place Calculations[C]. SPE Unconventional Resources Conference. Pittsburgh, Pennsylvania, USA: Society of Petroleum Engineers, 2010.

[17] Y. Qi, N.S. Zhang, X.J. Ren, Experimental study on the hydroscopicity of fracture reservoir, Journal of $\mathrm{Xi}^{\prime}$ an Shiyou University Natural Science Edition, 20(2005) 34-36. 